added to the known record; the majority of these have, in fact, been added in the past seven years. Not only is the sheer volume of the new material staggering but many long-cherished theories and dogmas have been challenged, if not discredited. Thus, even specialists now have a difficult time keeping abreast of newly discovered fossils, new sites and new interpretations. Michael Day is an exception, however, as the third edition of the Guide to Fossil Man clearly shows.

As in the earlier editions of the Guide, Professor Day has set a style as remarkable for its brevity as for its content. The basic data of about 40 fossil sites is conveyed in concise yet readable paragraphs. Data on taxonomic (or vernacular) synonyms, dating, faunal and archaeological associations, taxonomic affinities and morphology, are quickly available. A comprehensive bibliography accompanies each site entry and most of the fossil hominids are well illustrated. The sites included have been selected for their interest and importance from a large number of possibilities. Thus, although the Guide is less complete than the Catalogue of Fossil Hominids (reviewed in Nature, 270, 766; 1977) it is of more immediate and broader interest than those encyclopaedic volumes.

\section{Birds of the Western Palearctic}

Handbook of the Birds of Europe, the Middle East and North Africa: The Birds of the Western Palearctic. Vol. 1: Ostrich to Ducks. Edited by S. Cramp, K. E. L. Simmons, I. J. Ferguson-Lees, E. M. Nicholson, M. A. Ogilvie, P. J. S. Olney, K. H. Voous and J. Wattel. Pp. 722. (Oxford University: Oxford, London and New York, 1977.) £25.

THIs volume is the first of seven planned to cover the birds of the Western Palearctic (in spite of its cumbersome title, the work has been known as BWP for the many years of its planning and gestation). As such it follows a very illustrious predecessor, The Handbook of British Birds (Witherby et al. 1938-41). Although there were later editions of the work, the changes were relatively minor. The Witherby Handbook has been, and indeed still is, the standard work for many western European countries. No other work has replaced it, though a Swiss work (Handbuch der Vogel Mitteleuropas by Bauer and Glutz, 1966 et seq.) is currently in progress.

Plainly, the Witherby Handbook has become progressively more out of date; the work under review is intended to replace it. The main alteration in design is to include a greatly increased area of the Palearctic, from roughly $20^{\circ} \mathrm{N}$ to $50^{\circ} \mathrm{E}$ (Greenland is excluded). The choice of such a southern limit, although conform-
Although the format of the Guide is concise, a considerable amount of information is conveyed in the categories of morphology and phylogenetic affinities. These sections are particularly informative and useful, as Professor Day, unlike many authors of books on fossil man, has personally examined much of the original material. Such first hand acquaintance with the fossil evidence considerably enhances the authority of these sections.

Although designed as a source book, rather than as a text, the format and content of the Guide nevertheless allows it to be used successfully in the classroom. Experience with the earlier editions has indicated that students appreciate the easy availability of descriptive and historical data and the accessible bibliographical information. The expanded summary areas, covering the Neandertal 'problem' and the affinities of the australopithecines as well as listings of the new material, has augmented these strong points.

All in all, the Guide to Fossil Man is a useful and readable handbook for anyone interested in human evolution.

\section{G. E Kennedy}

G. E. Kennedy is an Assistant Professor in the Department of Anthropology at the University of California, Los Angeles.

ing with certain other authors, involves the work with a few poorly known north African species (such as the Ostrich) which are hardly part of our avifauna; one slightly wonders why a more northerly southern limit, such as the edge of the Sahara, was not chosen.

This work, as the previous one, is the product of a team of workers, British and Dutch. Each of the 122 species covered in this volume gets a section to itself. These average about 4-12 pages of text, though a few vagrants which have not occurred recently get much shorter treatment. For each species, separate sections cover Field Characters and Habitat, Distribution and Population, Movements, Food, Social Pattern and Behaviour, Voice, Breeding, Plumages, Moult, Measurements, Weights, Structure and Geographical Variation. The text is well documented with key references.

Also, for each species, except the vagrants, there are normally two maps and two diagrams. The two maps cover the world distribution and, on a larger scale, the distribution within the Western Palearctic. The latter shows summer and winter distributions in red and grey, respectively. These are not always very clear; small pockets of wintering ground, grey on a basically grey map, are difficult to see and the seriously colour-blind may have trouble distinguishing red (summer) from red on grey (resident all the year round). The two diagrams are a voice sonogram and a clockface type of diagram, showing patterns of migration, breeding, moult, and so on, for the species throughout the year. Personally, I find this rather too small to read easily; in addition, it has to be read with care, as the seasonal activities of a given species may be quite different in, for example, North Africa and Scandinavia.

Each species is depicted in colour, showing the bird in different plumages where distinguishable (summer, winter, male, female, juvenile, and so on). The 108 plates are by a number of different artists and not all are equally pleasing to my eye: many are packed rather tightly with birds; in particular, I find the downy young of some of the shearwaters and petrels unsatisfactory. In addition, the text often includes line drawings of the birds in behavioural postures.

The above gives, hopefully, an adequate description of the book and its contents. It is perhaps worth considering the value of such a book, particularly as, when complete, it is going to be an expensive work. Handbooks, by their very nature, are summaries of the available literature; a source of quick information or a starting point for further searches. Whole monographs or handbooks exist for many of the taxa of birds or even species dealt with in this volume; this is especially true for the wildfowl on which there is an enormous literature. Thus, of necessity, the writing of a handbook becomes an exercise in condensation: as time goes on this becomes increasingly more difficult; more has to be omitted. Certain of these difficulties are apparent when comparing this work with the earlier Handbook. Although larger, the text seems more compressed, more turgid.

However, the complaints are very minor; the present volume provides a wealth of information which is available nowhere else except in extensive libraries. There simply is no serious rival for the English reader. If one was prepared to be satisfied with much simpler information, I would recommend The Popular Handbook of British Birds (Hollom, latest edition 1977, $£ 5.50$ ), a single volume based on the Witherby work. For greater detail there is no alternative. The Swiss work mentioned above would be a serious rival for German-speaking ornithologists, but despite its qualities, the latest volume (no. 7 of 13) costs about $£ 45$.

One can be confident, therefore, that this work will become a standard reference. Although the physical production of the review copy is open to some criticism (the tops of some plates are cut off and the spine seems weak), the book is otherwise well produced and pleasingly free from errors. It contains a wealth of information and is a worthy successor to an illustrious ancestor. C. M. Perrins

C. M. Perrins is Director of the Edward Grey Institute of Field Ornithology, University of Oxford, UK. 